\title{
Lenguaje y realidad en Clément Rosset y Juan Rulfo.
}

\section{Language and reality in Clément Rosset and Juan Rulfo.}

\author{
Esta obra está bajo una Licencia Creative Commons Atribución 4.0 Internacional.
} DOI: $10.32870 /$ sincronia.axxii.n74.12b18

\section{Carlos Huerta Ornelas \\ Instituto de Investigaciones Filosóficas "Luis Villoro" / Universidad Michoacana de San Nicolás de Hidalgo \\ noircho@hotmail.com \\ (MÉXICO)}

Recibido: $15 / 03 / 2018$

Revisado: $20 / 03 / 2018$

Aprobado: 13/06/2018

\section{RESUMEN}

El presente texto tiene por objeto una aproximación centrada en la relación entre el lenguaje y la realidad. La pregunta de si el lenguaje puede hacer referencia a la realidad nos lleva a la consideración de aquella realidad que está pegada a la palabra, sin referencia exterior y aquella realidad que está detrás de la palabra, constituyéndose en su fundamento y sobre el que recae el criterio de verdad; se trata, por tanto, de una distinción entre la palabra grandilocuente y la palabra breve sin más. Se parte de la consideración de la obra de Juan Rulfo como una poética portadora de una visión de la realidad de grandes implicaciones filosóficas. El modo en que se aborda se corresponde a los objetivos propuestos de indagar las relaciones que podrían establecerse entre la literatura rulfiana y la realidad, en el marco de la teoría filosófica de lo real de Clément Rosset.

Palabras clave: Grandilocuencia. Representación. Ontología. Lo real.

\section{ABSTRACT}

The present text takes as object an approximation focused on the relation between the language and the reality. The question of if the language can refer to the reality takes us to the consideration of that reality that is stuck to the word, without exterior reference and that reality that is behind the word, being constituted in his ground and on that falls the criterion of truth, it concerns, therefore, of a distinction between the grandiloquent word and the brief word simply. It proceed of the consideration of the Juan Rulfo's work as a bearer poetics of a vision of the reality of big philosophical implications. The way in which it is approached corresponds to the proposed objectives 
of inquiring the relations that might be established between the rulfiana literature and the reality, in the framework of the philosophical theory of the real of Clément Rosset.

Keywords: Grandstanding. Representation. Ontology. The real.

\section{Introducción}

Al decir de Gadamer (1999), al principio la palabra y la cosa gozaban de una íntima unidad, el nombre era parte de aquello que lo portaba. Incluso, comenta, el vocablo "palabra", en griego ónoma, significa al mismo tiempo nombre, nombre propio, de tal manera que parecía que el nombre pertenecía al ser mismo, como si fuesen una y la misma cosa. Sin embargo, un poco más adelante escribe que la filosofía griega inició sabiendo que la palabra es sólo nombre, es decir, que no representaba al verdadero ser de aquello que lo portaba. Foucault (1968) por su parte, escribe que el lenguaje desde que surgió arrancado del grito, ha mantenido una función representativa, siempre ha nombrado, como mostrando con el dedo, lo cual, es una indicación y no un juicio. Después expresa que llegó la época en que el lenguaje rompió su viejo parentesco con las cosas para caer a una soberanía solitaria de la que ya no saldría nunca; las cosas por su parte, se recluyeron en su identidad irónica, es decir, no siendo más que lo que son. Las palabras ya no marcaron las cosas, la semejanza quedó frustrada y la palabra vacía.

Con esto de fondo, simplemente se pretende apuntar la compleja relación que pervive entre el lenguaje y la realidad, cuestión que se puede rastrear desde el Cratilo de Platón, en el que se intenta determinar si la relación que mantienen las palabras y las cosas es de coincidencia natural o, por el contrario, fruto de algún tipo de convención.

Ante esto, Rosset expresa que ordinariamente hacemos un uso del lenguaje sabiendo cómo funciona en determinados casos y cómo en otros, sin embargo desconocemos en general qué lo hace funcionar, en qué consiste y cómo podemos definirlo; lo hablamos pero no lo comprendemos:

Una divertida anécdota, que me ha contado Gilles Deleuze, que estaba presente aquel día, me parece ilustrar de maravilla la naturaleza de esta paradoja (hablar sin comprender) que es, a mi parecer, la paradoja central del pensamiento de Wittgenstein. 
Durante una defensa de tesis doctoral de filosofía, el impetrante, debilitado tras varias horas de esas picas que se usan en ese combate casi taurino, recibió de pronto una de aquellas estocadas, igualmente rituales, que deben en principio entrañar la muerte del combatiente. Un miembro del jurado preguntó al candidato: “Usted habla corrientemente el alemán, ¿no es cierto?” Frente a esta pregunta-trampa, el candidato, que perdía pie, improvisó una respuesta asombrosa: “¿El alemán? Lo hablo, claro - pero no lo comprendo." Este lapsus de un hombre acorralado, que hizo reír a jurado y auditorio, tiene más sentido del que parece. Apenas modificado, podría servir de divisa al conjunto del pensamiento de Wittgenstein: “¿El lenguaje? Lo hablo, pero no lo comprendo." (Rosset, 2011, p. 60)

Habrá que añadir a esto, que para Rosset no existe diferencia alguna entre el hecho de pensar y el hecho de hablar o escribir, pues considera que el pensamiento no preexiste a la palabra, ni es sólo su 'manifestación' sino que es el pensamiento mismo en tanto que sólo hay pensamiento a partir de que se constituye por la realidad de las palabras. De tal manera son indiscernibles que donde falta uno de los dos, desaparece el otro.

Ahora bien, bajo la consideración de $\operatorname{Rosset}^{1}$, por principio, hablar de lo real es perderlo. No obstante, aunque el caso común es que la palabra prescinde de toda referencia a cualquier realidad, de manera excepcional, hay palabras que logran, tanto mejor o tanto peor, remitirnos a cierta realidad. En otras palabras, si se da por sentado el hecho de que ninguna palabra da cuenta cabal de la realidad que señala, habrá que distinguir en qué casos la palabra conserva o no cierta referencia a la realidad aludida. Para esto se tendría que hacer una distinción sobre dos clases de realidad, aquella que está pegada a la palabra y desaparece con ella, realidad hecha de palabras, sin referencia exterior, y aquella que permanece detrás de la palabra y que en el mejor de los casos, llega a sugerir. La valoración que se podría hacer de ambas realidades sería en función de su

\footnotetext{
${ }^{1}$ Es conveniente hacer notar que para Clément Rosset, las nociones de lo real, el ser y la existencia son sinónimas e intercambiables, por lo que no establece alguna diferencia ontológica entre lo real y la realidad, pues ambas tienen la cualidad de ser, de existir.
} 
"contenido en realidad", esto es, que no designa la realidad de la cosa, sino lo que la cosa tiene de realidad; es decir, mientras una es pura representación sin arraigo, sin referencia, la otra alcanza a referenciar una realidad exterior. En el primer caso, Rosset considera que aquella palabra que no alude a ninguna realidad exterior es la palabra grandilocuente; en contrapartida, la palabra que sí logra referir a cualquier realidad exterior, sería la palabra sobria y moderada.

La grandilocuencia, en tanto palabra desmesurada según su etimología, se constituye como un desliz del lenguaje, que en su pretensión de traducir lo real a través de palabras, pierde toda relación con aquello que le daría sustento y legitimación. Exceso que también podría presentarse en una escritura sobria y moderada cuando conlleva la pretensión de reforzar la exageración en la pura simpleza, lo cual sería no su disminución sino su colmo. La consecuencia de este exceso es la disociación irrevocable de las palabras y las cosas. Es la pretensión de otorgar primacía a la palabra sobre la realidad, quedando el criterio de verdad en la palabra y no en la realidad que representa. Hay pues un desplazamiento en el que ya no se trata de una coincidencia sino una suplantación de la realidad, quedando sólo la realidad de la representación. La grandilocuencia, en este tenor, se considera lograda cuando ya no referencia a la realidad que supuestamente representa, cuando ha consumido la realidad exterior y tan sólo conserva su realidad interior, su discurso, quedando la representación como signo de sí misma.

Por otra parte, es conveniente dejar en claro que se entiende que hay escrituras que mantienen una total ajenidad a cualquier realidad exterior, en las que se despliega toda una gama de recursos retóricos y estilísticos que las libera de toda pretensión de anclaje en lo real; niegan cualquier similitud con cualquier realidad que no sea la propia de su discurso, que no obstante, mantienen un cierto aire de realidad. Estas escrituras no evocan objetos reales, los crean en su propia realidad. En estos casos, no hay supresión de realidad puesto que no es considerada; de hecho, aspiran a prescindir de ella. Hay, ciertamente una exagerada atención de sí, de su discurso, y, a la par, una exagerada despreocupación hacia lo real. 
Ahora bien, de cara a la grandilocuencia, tenemos la sobriedad y moderación de aquella palabra breve que logra referir a lo real. Sería aquella palabra que cuenta con el respaldo de lo real, lo cual constituye la excepción, al quebrantar los principios de la grandilocuencia que consisten en la supresión de cualquier realidad. Es la palabra de brevedad sin más, que mantiene una referencia a cualquier realidad exterior, en la que la separación de la representación y lo representado es mínima. En estos casos, se tendría una escritura que podría ser considerada como estética en función de su contenido en realidad. Y es en este tipo de escritura en la que podríamos fundamentar el criterio de verdad, pues "la expresión de la verdad tiene los mejores títulos para constituirse en un valor que puede aceptarse como criterio estético" (Rosset, 2004, pp. 159-160).

\section{La palabra en Rulfo, una brevedad sin más}

Al tenor de lo hasta aquí expresado, bien podríamos poner en Rulfo las palabras de Foucault (1979, p. 162): "me doy cuenta que no he escrito más que ficciones. No quiero, sin embargo, decir que esté fuera de verdad." Se trata, por tanto, de una verdad que ya no descansa en la palabra sino en la realidad, una verdad ontológica que es la condición de posibilidad de cualquier verdad epistemológica o enunciado veritativo. Es en este horizonte en el que podemos situar la escritura rulfiana, que se encuentra en las antípodas de la grandilocuencia, que, al contrario de esta, hace recurso de una escritura sobria y moderada, de brevedad sin más y, que al decir de Rosset, es la palabra que logra una rara y feliz representación de lo real.

Ciertamente queda asentado que toda palabra es portadora de significado. En este tenor, la escritura de Rulfo, por su fragmentariedad, se puede considerar, trata de minimizarlo; que si bien se mira, constituye una palabra que no dice casi nada, pero por lo mismo lo dice casi todo. También se comprende que, según lo dicho por Rosset, la sobriedad y moderación pueden constituirse en un lenguaje grandilocuente por disminución, mas no en el caso de Rulfo, que tiende más bien al silencio y no al colmo de la grandilocuencia. Antes bien, sería la pretensión de dejar lo representado en su mutismo esencial. Su prosa no sugiere un sentido oculto sino una significación inmediata, 
silente, sin promesa. Nos señala la existencia en su simplicidad, lo que es, sin prórroga que nos exima de la actualidad de lo real, siempre presente, en tanto dado y actual, sin dar pie a la añoranza de una ausencia, es decir, nos otorga el sentimiento -en su acepción de un darnos cuenta, de un saber-, que en realidad todo está dado. Aquí está la rosa, aquí hay que bailar, nos dice Hegel.

Si bien la propuesta estriba en que la escritura de Rulfo alude a la realidad, parece acertado aseverar que en otros momentos prescinde de ella; por lo cual podríamos situarla en aquellas escrituras que haciendo recurso a la phantasía, hacen posible que su poética se mantenga en la realidad de su propio discurso, pues carecen de un valor referencial, y sobre las que no pesa ningún valor de verdad. Estas escrituras mantienen una total independencia de cualquier otra realidad, por lo que no hay en ellas evocación alguna sino creación total.

Bajo estas consideraciones respecto de la escritura rulfiana, se podría expresar que Rulfo no narra, describe, pues como expresa Lukács (1966) la narración articula y la descripción nivela, entendiendo por ello, que la narración es la escritura que tiene por pretensión dar un todo coherente en el que acorde a criterios formalistas conforma una estructura en la que existen jerarquías discursivas, en las que no tienen el mismo orden de relevancia los sujetos de la acción que los objetos accesorios o contextuales. Mientras que por el lado de la descripción, la escritura, fuera de todo formalismo tiene la pretensión de dar las cosas tal como son percibidas, sin jerarquías discursivas, en una total democracia referencial, pues no hay sujeto de acción sino que la acción lo es todo, pues como dice Lukács (1966, p. 190), “la descripción lo hace todo presente.” Así, nos encontramos que los personajes rulfianos "que no alcanzan la categoría de sujetos -aunque estén individualizados- sino de sensaciones intensivas" (Piña, García, Jara, Moure y Secreto, 2008, p. 47) describen, a través de la evocación del pasado, lo que son las cosas, es decir, el presente de lo real, que no es más que la intensidad de lo real en la confluencia de pasado y presente. A la consideración de Lukács, quien tiene la pretensión de destacar la narración por encima de la descripción, "el hecho de que se describa con la misma minuciosidad lo importante y lo insignificante [...] arrastra todo lo humanamente significativo" (Lukács, 1966, p. 192). Bajo esta 
consideración, la narración, por tanto, sería el ámbito de la significación y la coherencia. De ahí que podamos entender que para Rosset lo real es libre de connotaciones, mientras que la representación conlleva, razonablemente, una gran riqueza de connotaciones y significados que se añaden a la realidad; y en Rulfo podemos ver que su escritura descriptiva otorga un mismo nivel de relevancia a lo descrito, sea un personaje, el viento, un pueblo o, incluso, el ladrar de los perros. La relevancia de las cosas ya no pende de la acción humana, un sentido otorgado, sino que éstas adquieren su sentido propio, que no es más que su ser. Dejan de ser vehículos para conformar una acción rectora que les otorgaría sentido. En Rulfo, por tanto, existe una democracia ontológica, pues en su obra no hay héroes sino personas comunes y corrientes que se corresponden a la realidad, en el que cualquiera se puede ver reflejado, ciertamente no en tanto a las mismas formas de vida sino en relación al sentir ante la realidad que mantiene una total ajenidad respecto de toda pretensión y esperanza humanas. La escritura de Rulfo, podría considerarse, por tanto, como una palabra breve que no pretende constituir un todo coherente, pues mantiene una brevedad descriptiva que sugiere, y no una emisión judicativa que sería más una argumentación lineal y coherente propia de la narración.

\section{Consideraciones finales}

Si bien hemos abordado periféricamente la prosa de Juan Rulfo en el marco de la teoría de lo real de Clément Rosset, ha sido con la pretensión de aproximarnos únicamente a su escritura, a la luz de la problemática relación que mantiene el lenguaje respecto de la realidad. Ambos autores, de manera creativa y con sus propios medios, mantienen un interés común: la realidad. Asimismo, priman la verdad ontológica de lo real. Aluden a una realidad que se retrae, por su singularidad, ante toda pretensión de definición. Y es en este tenor que la poética rulfiana podría entenderse como aquella representación, que a través de la brevedad, sobriedad y moderación de una escritura silente logra señalarnos la realidad. En ello estriba a nuestro parecer la esencia del realismo de Rulfo. 
Finalmente, ante el planteamiento de Rosset sobre la cuestión de saber si el destino de toda palabra consiste en desprenderse de lo real y constituirse en signo de sí misma, parece ser la norma, pues toda palabra siempre dice un poco de más, lo cual constituye su impotencia de decir, cabalmente, lo que trata de decir. No obstante hay un resquicio en el que las palabras pueden establecer un vínculo con la realidad que les ha dado origen. Esa hendidura hace posible que ciertas palabras, cuando se dicen oportunamente y con arte, pueden evocar, de tarde en tarde, una cierta sensación de lo real.

\section{Referencias:}

Foucault, M. (1968), Las palabras y las cosas. Una arqueología de las ciencias humanas, Buenos Aires: Siglo XXI Editores.

Foucault, M. (1979), Microfísica del poder, Madrid: La Piqueta.

Gadamer, H.-G. (1999), Verdad y método I, Salamanca: Ediciones Sígueme.

Lukács, G. (1966), Problemas del realismo, México, D. F.: Fondo de Cultura Económica.

Piña, C.; García, A .M.; Jara, S.; Moure, C.; y Secreto, C. (2008), Literatura y (pos) modernidad: teorías y lecturas críticas, Buenos Aires: Biblos.

Rosset, C. (2004), Lo real. Tratado de la idiotez, Valencia: Pre-Textos.

Rosset, C. (2011), El demonio de la tautología, seguido de cinco breves piezas morales, Madrid: Arena Libros. 